\title{
0 processo de alfabetização realizado na Escola da Ponte: relato de uma experiência reveladora
}

\section{The literary process at Escola da Ponte: a report about a revealing experience}

Mayara Rodrigues é aluna do curso de Licenciatura em Pedagogia

pela Universidade Federal de São Carlos e atualmente faz

intercâmbio acadêmico na Universidade do Minho, localizada

no Norte de Portugal. Atuou na rede particular de ensino como

professora bilíngue no Ensino Fundamental I.

Contato: mayarar27@gmail.com

\section{Resumo}

0 presente trabalho constitui-se em um relato de experiência em um espaço de aprendizagem do Núcleo de Iniciação na Escola Básica da Ponte, em Portugal. 0 foco foi dado no processo de alfabetização desenvolvido e suas particularidades. Tendo seus princípios pedagógicos alicerçados em valores como solidariedade, responsabilidade e democraticidade, a Escola da Ponte orienta sua prática escolar em formar cidadãos criativos e autônomos, capazes de transformar positivamente o meio onde vivem. Nesse sentido, qual seria a importância e o espaço dado para o processo de alfabetização em uma escola onde se são pregados a não seriação e a mistura de faixas etárias? A busca por essa resposta possibilitou a compreensão das diferentes dinâmicas que permeiam o cotidiano escolar da Escola da Ponte e que influenciam diretamente o desenvolvimento da autonomia e a ampliação da visão de mundo de cada aluno que ali estuda.

Palavras-chave: Escola da Ponte. Alfabetização. Autonomia.

\section{Abstract}

This paper aims to present a report experienced in the Center of Initiation of Escola Básica da Ponte, in Portugal. 
The focus was on the literacy process developed thereand its peculiarities. Having its pedagogical principles grounded mainly in values such as solidarity, responsibility and democracy, Escola da Ponte guides its school practices to form creative and autonomous citizens, able to positively transform the environment in which they live in. The proposed question is: What would be the importance of literacy, or the opportunity given to the process of literacy in a school with no grading and mixed age systems? The search for this answer allowed us to understand the different dynamics that permeate the daily school routine at Escola da Ponte, that directly influence the development of autonomy and the expansion of an world vision by each student. Keywords: Escola da Ponte. Literacy. Autonomy.

\section{Introdução}

Conhecida por seu arrojado Projeto Educativo, a Escola Básica da Ponte destaca-se no cenário educacional como uma instituição que promove a autonomia e a consciência cívica de seus alunos. Uma experiência pedagógica única que alcança não só os alunos, mas sua comunidade, e que cada vez mais se destaca como um centro de formação para educadores de todo o mundo.

Localizada atualmente na Vila São Tomé de Negrelos, no norte de Portugal, e inserida no sistema público de Educação, a escola recebe alunos de todas as regiões do país, acolhendo inclusive alunos de diferentes nacionalidades. Além disso, mesmo eng'lobando o ensino pré-escolar e os $1^{\circ}, 2^{\circ}$ e $3^{\circ}$ ciclos (no Brasil, Educação Infantil e Ensino Fundamental), a escola não trabalha com séries ou turmas, mas adota uma organização por núcleos de ensino/aprendizagem, sendo estes a Iniciação, Aprofundamento e a Consolidação (PORTUGAL, 2016). Os alunos, por sua vez, transitam por esses núcleos de acordo com suas competências, capacidades e maturidade, respeitando-se um perfil que leva em consideração fatores individuais, como seu ritmo de estudo, seus valores, o nível de autoconhecimento e competências gerais.

A Escola da Ponte, como é mais popularmente referida, atende crianças com diversas necessidades pedagógicas, caracterizandose também como uma escola inclusiva.

Desde fevereiro de 2016tenho o prazer de estagiar na Escola da Ponte, podendo vivenciar sua dinâmica, interagir com culturas 
plurais que lá existem e observar práticas pedagógicas que enriquecem minha formação de maneira efetiva e reflexiva. No entanto, meu primeiro relato sobre essa experiência pedagógica terá o foco em algo que, para mim, foi surpreendente: o processo de alfabetização realizado na Escola da Ponte. Será esse processo também inovador?

Essa escola defende a ideia de respeitar o ritmo do aluno e de transformá-lo em protagonista do seu aprendizado; nesse sentido, qual seria a importância e o espaço dado para o processo de alfabetização em uma escola na qual são pregadas a não seriação e a mistura de faixas etárias?

A busca por essa resposta possibilitou diversas reflexões a respeito do processo de alfabetização desenvolvido na Escola da Ponte, o que promoveu uma análise crítica sobre o que foi observado.

\section{Sobre a rotina dos alunos}

0 processo de alfabetização da Escola da Ponte ocorre no núcleo chamado de Iniciação. Nesse núcleo estão as crianças entre 6 e 9 anos de idade; no entanto, a dinâmica de trabalho das crianças muda muito de dia para dia. Um dia, por exemplo, todos os alunos podem estar juntos trabalhando em grupos por interesse de tema; em outro dia, o grande grupo pode ser dividido em outros pequenos grupos de trabalho. 0 importante dessa dinâmica é o espaço em que ela acontece.

Os espaços de aprendizagem contam com paredes removíveis, podendo ser utilizadas como divisor do espaço e, por consequência, divisor dos grupos de acordo com as dinâmicas do dia a dia.

0 trabalho com as crianças que acabaram de deixar o préescolar é intenso e, geralmente, acontece mais vezes por semana num espaço específico para esse grupo. Nesses momentos, as paredes são essenciais para a concentração e o aproveitamento desses alunos.

Ao todo são 24 crianças no processo de alfabetização. Estas interagem entre si e também com as demais crianças dos outros núcleos de ensino. Essa interação acontece em diferentes momentos de sua rotina semanal, como nas vezes que recebem ajuda para a finalização de uma tarefa; assistindo a seminários/ apresentações audiovisuais preparadas pelos alunos já 
alfabetizados, chamado "momento de partilha"; durante o recreio, que é compartilhado entre todos no mesmo horário; nas reuniões de grupos de responsabilidade e também nas assembleias.

As reuniões de grupo de responsabilidade acontecem nas manhãs de sexta-feira. Os grupos são mesclados, contendo participantes de todos os núcleos. Cada aluno, bem como os orientadores educativos, é responsável por algum aspecto funcional da escola. Nessas reuniões os alunos discutem ações, resolvem assuntos e organizam sua responsabilidade de acordo com as necessidades da escola e deles próprios.

Já as reuniões de assembleia reúnem todos os alunos às sextasfeiras no período da tarde, e é nelas que os alunos debatem medidas, analisam e discutem ações de forma democrática, objetivando o bem comum.

No restante dos dias, as crianças, na grande maioria do tempo, ficam nos espaços de aprendizagens, quando não vão ao ginásio para a aula de Educação Física ou à sala de expressões plásticas para a aula de Educação Artística.

\section{Alfabetização: detalhes do processo}

Como já foi dito, as crianças que estão vivendo o processo de alfabetização fazem parte do Núcleo de Iniciação.

No início do ano letivo o professor traz imagens para que, por meio destas, frases de autoria dos alunos sejam criadas. As imagens são escolhidas pelo professor/tutor para que haja discussão sobre a escrita das palavras. Após a criação das frases, o professor destaca algumas letras que a turma estudará ao longo do ano.

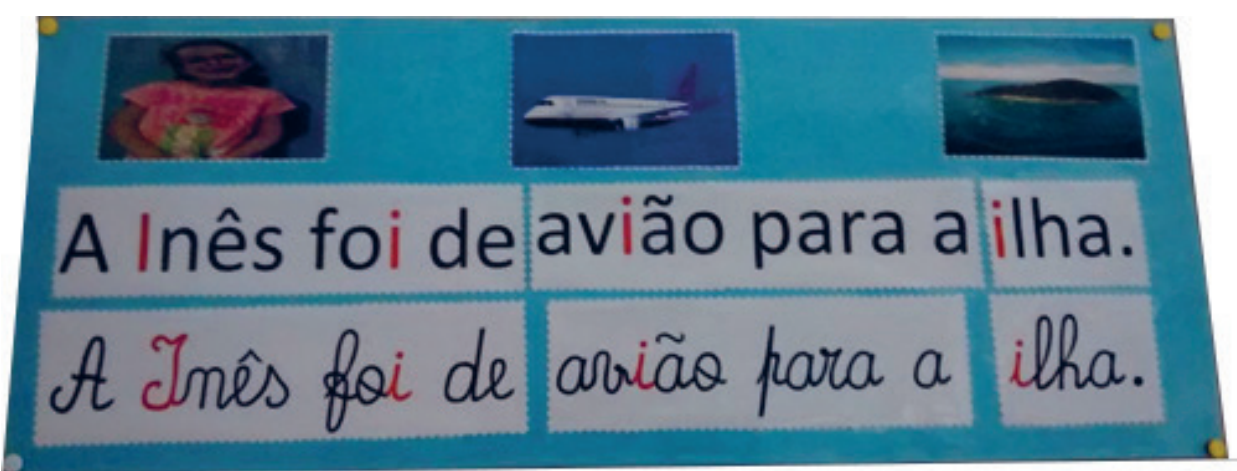

Figura 1 - Recurso visual para o processo de alfabetização (Escola da Ponte, Portugal) 
0 espaço da sala de aula fica repleto de recursos visuais para que no momento da escrita livre as crianças tenham referências.

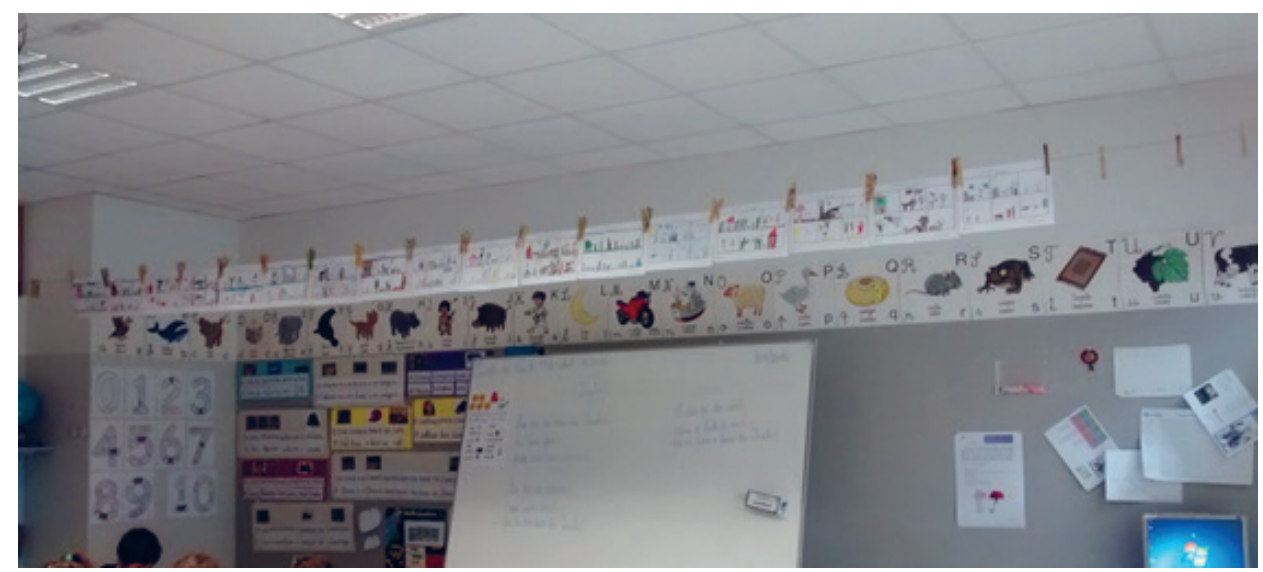

Figura 2 - Espaço de aprendizagem

A escrita criativa, como é chamada pelo professor/tutor, é o momento em que as crianças se arriscam na escrita por meio de exercícios de formação de frases, nos quais as palavras são dadas pelo professor.

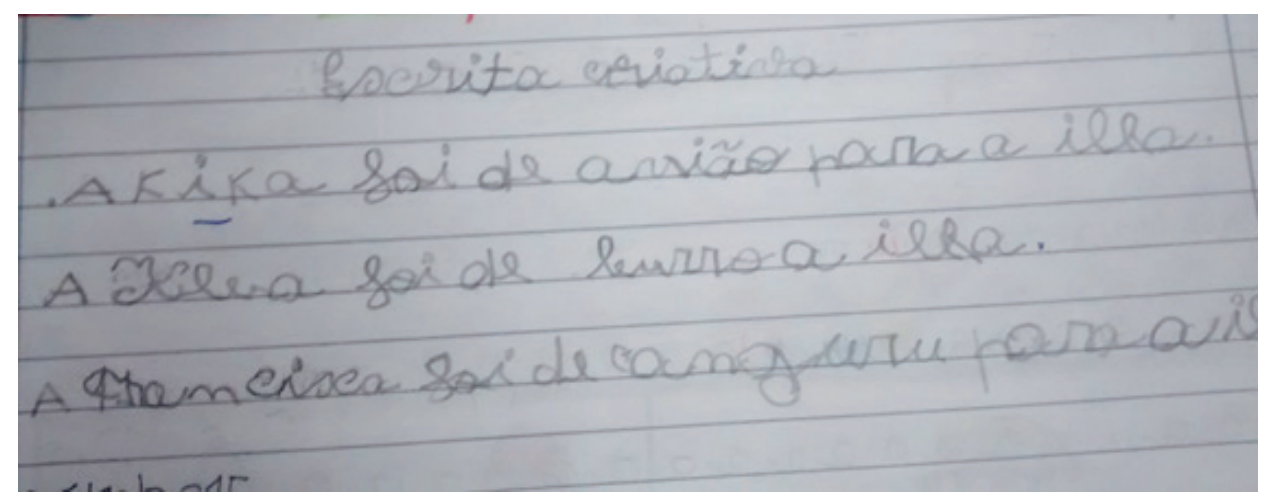

Figura 3 - Exemplo de escrita criativa

0 professor/tutor afirma que o registro visual faz toda a diferença para o processo de aquisição da escrita e, por isso, utiliza como estratégia a escrita coletiva no quadro, aproveitando também para ensinar o traçado das letras. Os alunos fazem também exercícios diários de caligrafia e coordenação motora.

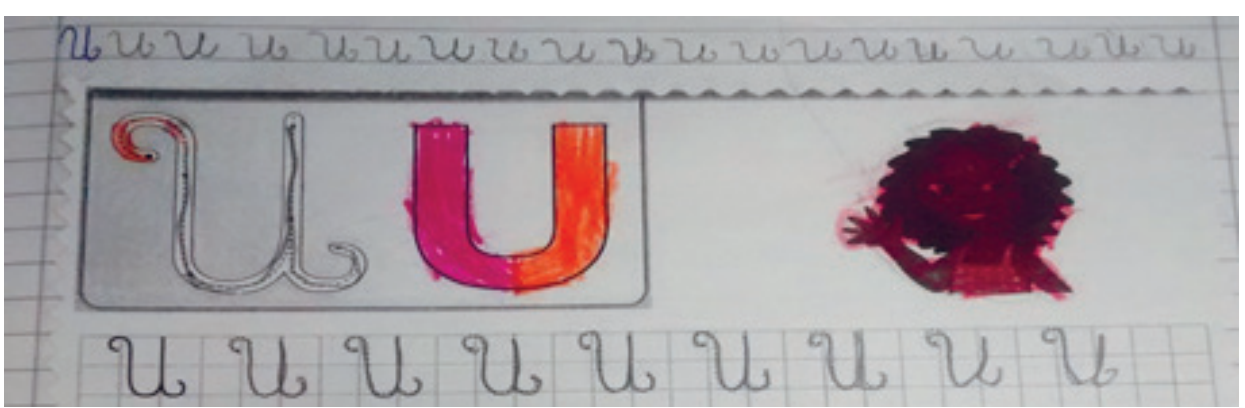

Figura 4 - Exercícios de coordenação motora 
A Escola Básica da Ponte tem seus princípios pedagógicos alicerçados principalmente nas ideias de Célestin Freinet (18961966), Pestalozzi (1746-1827), Carl Rogers (1902-1987) e Paulo Freire (1921-1997).

Assim, de maneira sintetizada, pode-se dizer que a escola orienta sua prática escolar em formar cidadãos criativos e autônomos, capazes de transformar o meio onde vivem, por meio do diálogo e da horizontalidade entre aluno-professor/tutor.

0 ano letivo em Portugal inicia-se no mês de setembro, e o trabalho é finalizado em junho. Em abril de 2016 era possível observar o avanço que alguns alunos tiveram desde o início do ano letivo até agora, seja na escrita, seja na leitura. Por meio da experiência, é possível perceber que há efetividade do trabalho desenvolvido na alfabetização. No entanto, é necessário fazer uma análise crítica do que foi observado e compartilhado neste relato.
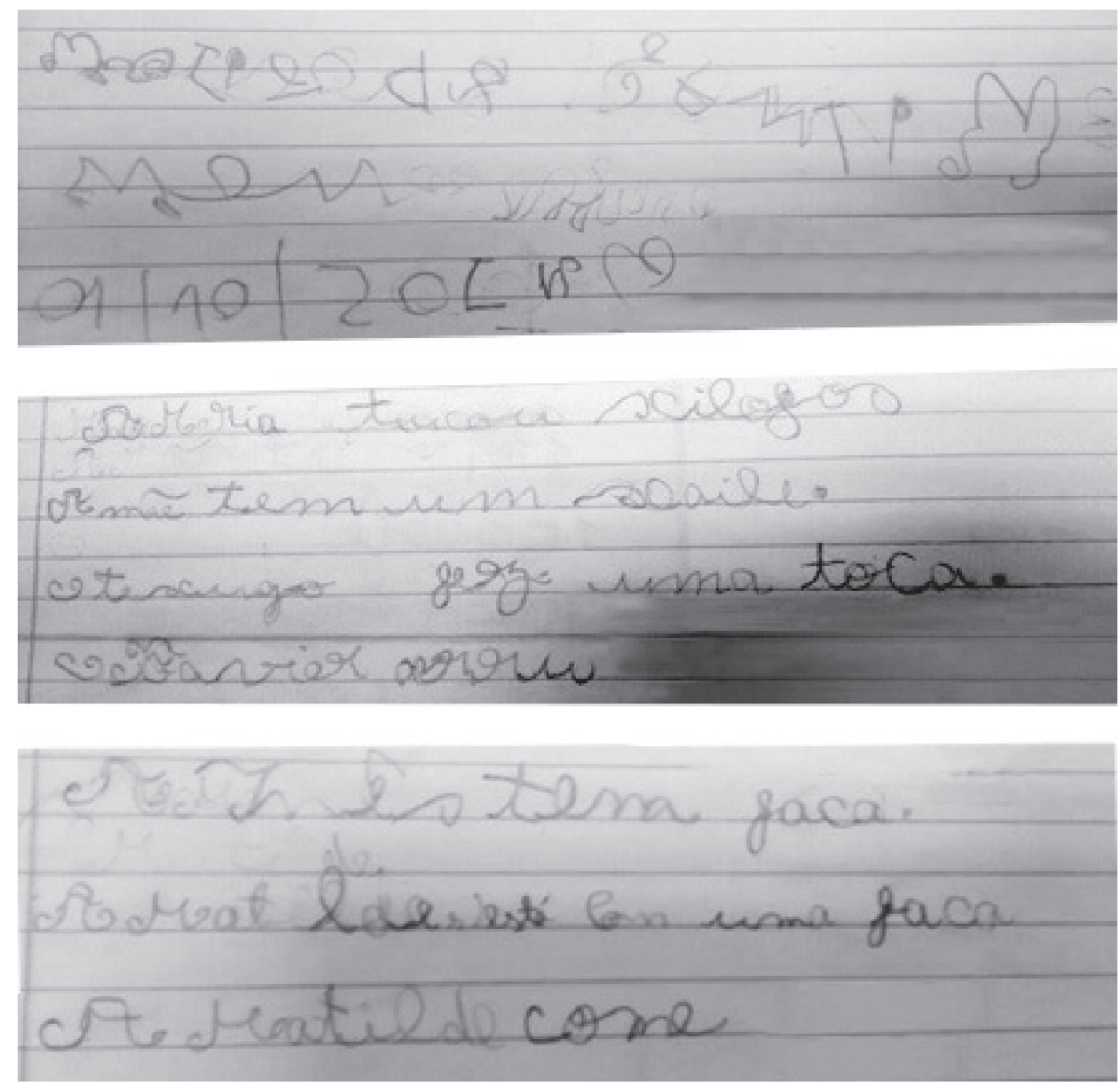

Figuras 5, 6 e 7: Processo de alfabetização de uma criança do Núcleo de Iniciação da Escola da Ponte, em três momentos: outubro de 2015, fevereiro de 2016 e abril de 2016. 


\section{Análise das observações}

A construção das frases por intermédio das imagens escolhidas pelo professor/tutor no início do ano letivo é de autoria das crianças. No entanto, essas imagens não estão relacionadas ao cotidiano destas, o que dificulta a atribuição de significado à escrita.

As imagens decorativas do alfabeto que se encontra exposto no espaço de aprendizagem se relacionam à primeira letra da palavra. São imagens que nos remetem às tradicionais cartilhas, que utilizam, por exemplo, o $\mathrm{G}$ de gato, o $\mathrm{R}$ de rato etc, na tentativa de facilitar a memorização das letras e sons. 0 professor/tutor recorre muitas vezes a esses apoios visuais.

Ainda podemos apontar outras práticas tradicionais presentes no processo de alfabetização realizado pela Escola da Ponte, como os exercícios de repetição do desenho das letras e de caligrafia de palavras descontextualizadas.

0 momento de escrita criativa proposto pelo professor/tutor também não caracteriza nenhum método inovador, uma vez que as crianças ao escreverem suas frases preferem buscar por palavras já introduzidas em seu "vocabulário de escrita" e que, muitas vezes, aparecem expostam no espaço de aprendizagem. 0 exemplo dado na figura 7 ilustra essa crítica. A aluna em questão formou frases com os nomes dos colegas de sala e com as palavras que estavam expostas nos recursos visuais que o espaço oferecia. Ao escrever a frase "a Helena foi de canguru para ilha", a aluna demonstra não se preocupar em formar frases com um significado real para ela mesma.

No entanto, é importante ressaltar que após escreverem as frases os alunos apresentam a tarefa para o professor/tutor, que por sua vez (quando necessário) solicita atenção na escrita das palavras "erradas", o que faz com que as crianças reflitam sobre suas frases e sobre a ortografia. Essa dinâmica não permite a reflexão sobre o erro, mas visa apenas o ensino do certo. Para Monteiro (2010, p.64), quando isso acontece "a criança acaba sendo adestrada, adquirindo as habilidades para dominar a escrita e leitura definida".

Ao ser questionado sobre qual método utilizava, o professor/ tutor afirmou que não se pode definir uma única abordagem. Seu trabalho permeia o método analítico e o sintético, além de receber influências do método natural proposto por Célestin Freinet. 
Monteiro (2010, p.61) ressalta que "o sucesso do desenvolvimento dos analíticos depende do aspecto interpretativo. 0 trabalho, envolvendo o método de sentenciação, se englobar apenas frases isoladas e descontextualizadas, também não vai contribuir para a leitura interpretativa".

Diante do que foi observado, é possível dizer que não há relação entre as práticas realizadas pelo professor/tutor e o método analítico citado por este ao ser questionado. É muito mais evidente o método sintético no trabalho realizado, no qual não há o incentivo interpretativo do que se lê e se escreve.

Sendo assim, também não é possível identificar o método natural de forma direta no processo, pois o método proposto por Freinet implica uma não programação do processo. Não há espaço para exercícios padronizados. A aprendizagem é dada de forma natural, em que há a valorização da intuição e hipóteses dos alunos (FREINET, 1977, p. 55).

Embora as práticas alfabetizadoras realizadas na Escola da Ponte não possam ser definidas como inovadoras, é necessário lembrar que essa instituição possui inúmeras estratégias para o desenvolvimento de valores como o respeito, responsabilidade e autonomia dos alunos, o que, por sua vez, torna o aprendizado humanizado e democrático. São elas, por exemplo, a assembleia, as reuniões de responsabilidade, os dispositivos pedagógicos, o pedido de palavra (o aluno vai à frente do espaço de aprendizagem e pede a palavra, geralmente para expor alguma necessidade, crítica ou pensamento), entre outros procedimentos.

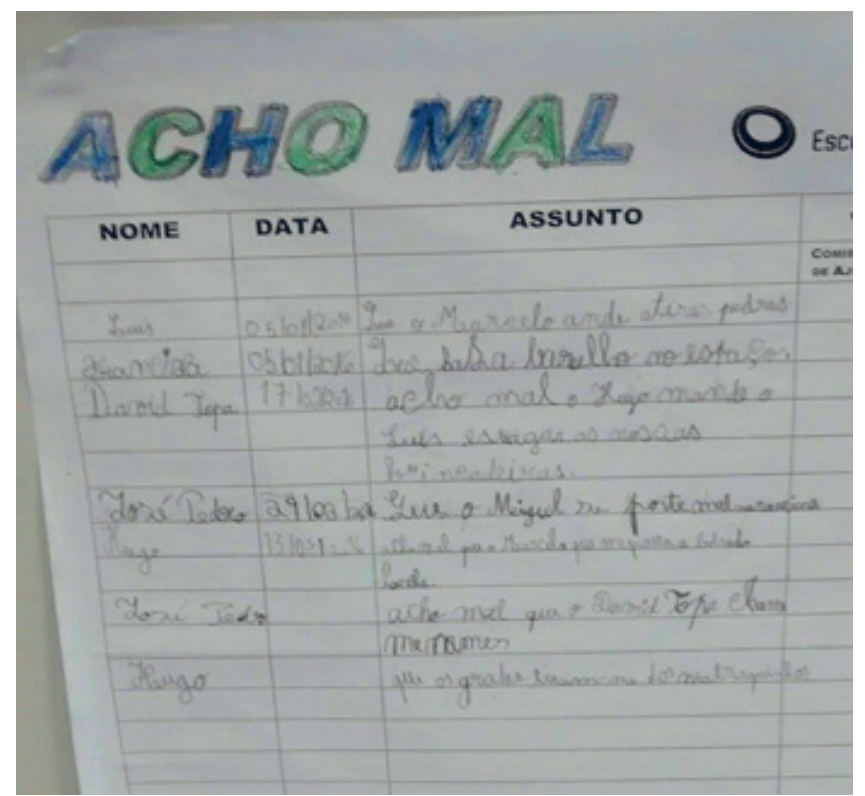

Figura 8 - Dispositivo pedagógico "Acho Mal" 
As crianças desde o pré-escolar já são estimuladas a pensar criticamente sobre atitudes que de, certa forma, agridam a cidadania. Assim, a exposição de opiniões, sugestões e reclamações fazem parte do dia a dia dos alunos, tornando-os membros ativos da comunidade escolar.

Segundo o professor/tutor, a maioria dos alunos termina o ano letivo com a leitura e a escrita adquiridos, podendo então serem transferidos para o espaço normal do Núcleo de Iniciação.

\section{0 processo de letramento}

Conforme o Regimento Interno da Escola da Ponte, em que podemos encontrar o principal objetivo do Núcleo de Iniciação, que é fazer com que as "crianças adquiram as atitudes e competências básicas que Ihes permitam integrar-se de uma forma equilibrada na comunidade escolar e trabalhar em autonomia, no quadro de uma gestão responsável de tempos, espaços e aprendizagens" (PORTUGAL, 2016), é possível reconhecer o conceito de letramento proposto por Soares (2001, p.18) nesse contexto: "Letramento é o estado ou a condição que adquire um grupo social ou um indivíduo como consequência de ter-se apropriado da escrita".

Nesse sentido, o processo de letramento está relacionado à integração emancipatória do aluno na comunidade escolar, dando acesso a novas relações sociais, culturais e ao conhecimento, que por sua vez ampliarão sua visão de mundo e autonomia.

Nos momentos de interação e expressões individuais críticas, como nas reuniões de responsabilidade e na assembleia, é possível notar com clareza a função social que o processo de alfabetização possui para esses alunos. As assembleias são esperadas ansiosamente por eles, e tanto a convocatória quanto a pauta da assembleia são divulgadas anteriormente à data do evento. Muitos alunos não alfabetizados pedem ajuda para os que já sabem ler para se inteirarem dos assuntos que serão discutidos.

Ainda sobre o processo de letramento, é de suma importância relatar que nas dependências da Escola da Ponte podemos observar a existência de uma cultura escrita que, segundo Britto (2005, p.19), caracteriza-se como "um modo de organização social, cuja base é a escrita". Por todos os lados da escola, nos deparamos com diferentes manifestações escritas e com a promoção da leitura. 


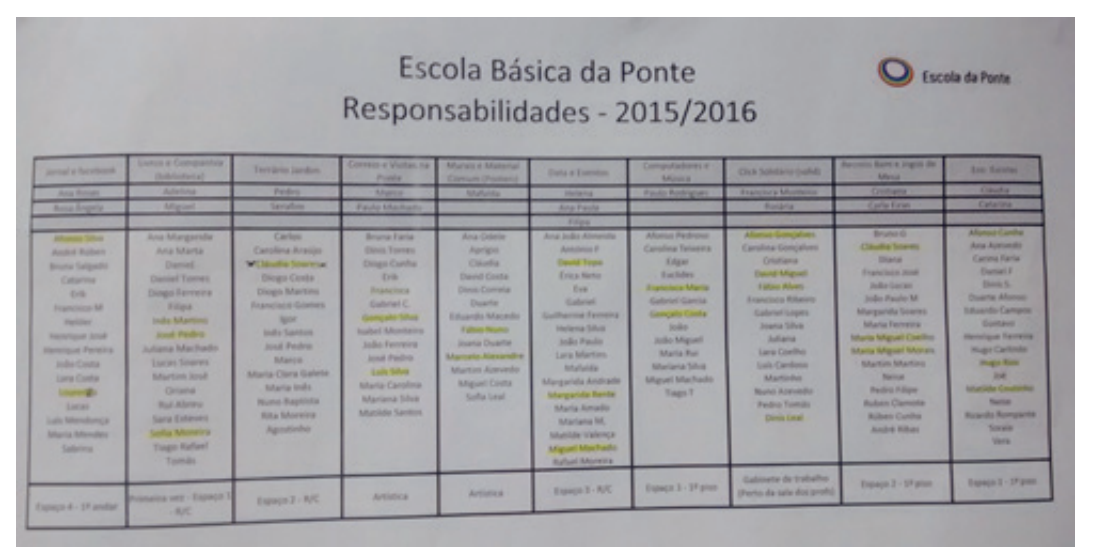

Figura 9 - Tabela de responsabilidades

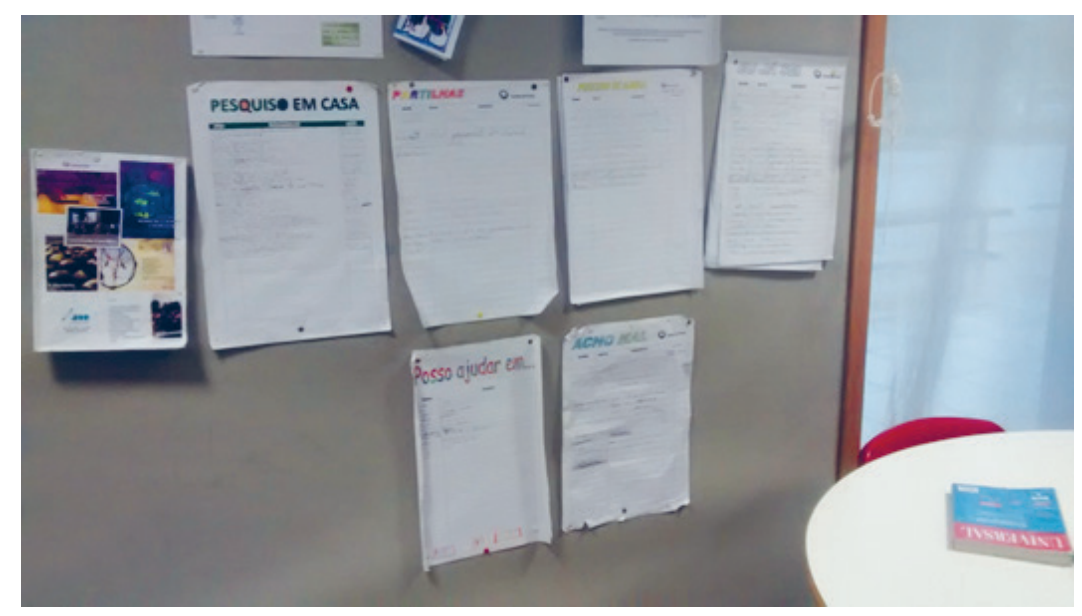

Figura 10 - Dispositivos pedagógicos

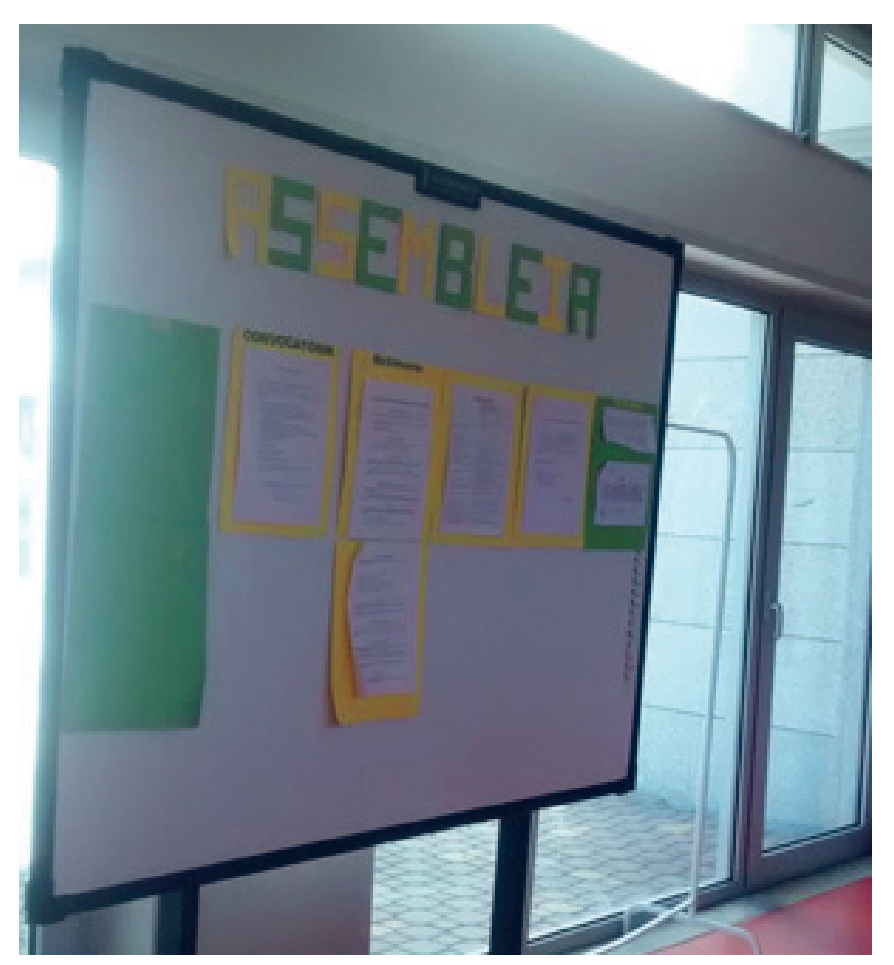

Figura 11 - Painel com convocatória para assembleia 


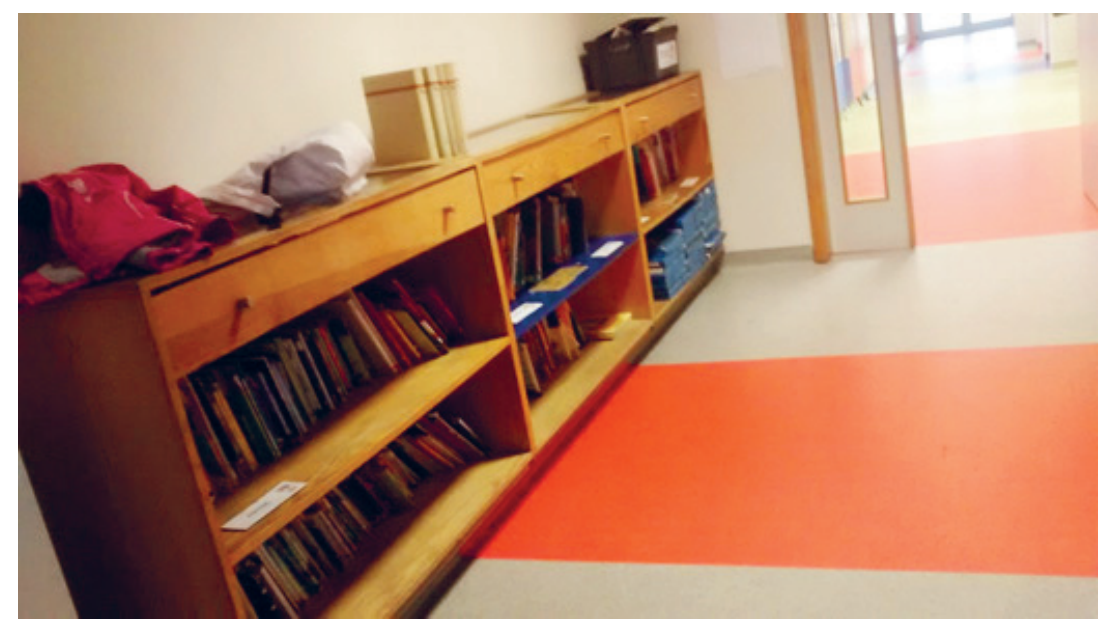

Figura 12 - Livros disponíveis pelos corredores da escola

Sendo assim, pode-se observar no trabalho realizado na Escola da Ponte que os processos de alfabetização e letramento são paralelos, mas, de certo modo, caminham juntos.

Uma vez alfabetizadas, as crianças começam a frequentar o "próximo nível" da Iniciação, no qual dividem o espaço com crianças de até 11 anos. Nessa altura do processo, os alunos já possuem autonomia necessária para iniciar a dinâmica de ensino/ aprendizagem característica da Escola da Ponte: a escolha dos conteúdos de estudo quinzenalmente (plano de estudos de quinzena) e diariamente (plano de estudos do dia).

\section{Considerações finais}

0 relato com foco no processo de alfabetização realizado na Escola da Ponte é revelador, pois desconstrói a ideia de que todas as práticas executadas nesta são inovadoras. No entanto, a experiência pedagógica não deixa de ser enriquecedora, tendo em vista as demais práticas arrojadas que podemos constatar e vivenciar nesse contexto.

De fato o método de caráter sintético, como base do processo de alfabetização, não soa de acordo com a proposta democrática e reflexiva da Escola da Ponte e seus objetivos pedagógicos, mas apresenta resultados satisfatórios no que diz respeito à habilidade de ler e escrever mecanicamente. É necessário considerar que esse processo tem continuidade ao longo de todo o Núcleo de Iniciação, no qual, após adquirirem a habilidade mecânica da escrita e leitura, os alunos passam a utilizar essa habilidade como instrumento de uma prática social ativa pautada no pensamento crítico e na cidadania transformadora. 
Finalizo ressaltando a importância do processo de letramento dentro do contexto da Escola da Ponte, pois essas são ferramentas primordiais para o desenvolvimento global do aluno em sua vida escolar nessa instituição; afinal, nada melhor que isso para promover autonomia e responsabilidade no futuro cidadão do mundo que será entregue para a sociedade.

\section{REFERÊNCIAS}

BRITTO, Luiz Percival Leme. Letramento e alfabetização: implicações para a educação infantil. In: FARIA, Ana Lúcia Goulart de; MELLO, Suely Amaral. (Orgs.). O mundo da escrita no universo da pequena infância. Campinas: Autores Associados, 2005. p. 5-21.

FREINET, Célestin. Método Natural I: a aprendizagem da língua. Tradução: Franco de Sousa e Maria Antonieta Guerreiro. Lisboa, Portugal: Editorial Estampa, 1977.

PORTUGAL. Ministério da Educação e Ciência. Regulamento Interno da Escola Básica da Ponte. Disponível em: http:// goo.gl/3rkleU. Acesso em: 24.jun. 2016.

SOARES, Magda. Letramento: um tema em três gêneros. Belo Horizonte: Autêntica Editora, 2001.

MONTEIRO, Maria lolanda. Alfabetização e letramento na fase inicial de escolarização. São Carlos: EdUFSCar, 2010. 64 p. (Coleção UAB - UFSCar).

Recebido em: 19/04/2016

Revisto em: 12/05/2016

Aceito em: 8/05/2016

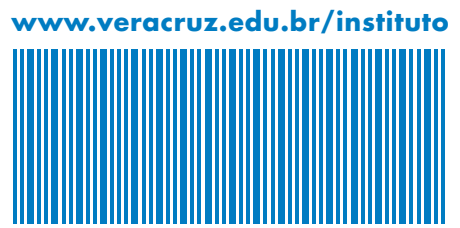

